\title{
Can salvage logging affect seed dispersal by birds into burned forests?
}

Josep Rost, Pere Pons, Josep M. Bas

Departament de Ciències Ambientals, Universitat de Girona, Campus de Montilivi, 17071 Girona, Catalonia, Spain.

\section{Abstract}

The recovery of vegetation in Mediterranean ecosystems after wildfire is mostly a result of direct regeneration, since the same species existing before the fire regenerate on-site by seeding or resprouting. However, the possibility of plant colonization by dispersal of seeds from unburned areas remains poorly studied. We addressed the role of the frugivorous, bird-dependent seed dispersal (seed rain) of fleshy-fruited plants in a burned and managed forest in the second winter after a fire, before on-site fruit production had begun. We also assessed the effect on seed rain of different microhabitats resulting from salvage logging (erosion barriers, standing snags, open areas), as well as the microhabitats of unlogged patches and an unburned control forest, taking account of the importance of perches as seed rain sites. We found considerable seed rain by birds in the burned area. Seeds, mostly from Olive trees Olea europaea and Evergreen pistaches Pistacia lentiscus, belonged to plants fruiting only in surrounding unburned areas. Seed rain was heterogeneous, and depended on microhabitat, with the highest seed density in the unburned control forest but closely followed by the wood piles of erosion barriers. In contrast, very low densities were found under perches of standing snags. Furthermore, frugivorous bird richness seemed to be higher in the erosion barriers than elsewhere. Our results highlight the importance of this specific post-fire management in bird-dependent seed rain and also may suggest a consequent heterogeneous distribution of fleshy-fruited plants in burned and managed areas. However, there needs to be more study of the establishment success of dispersed seeds before an accurate assessment can be made of the role of bird-mediated seed dispersal in post-fire regeneration.

Keywords: wildfire, frugivorous birds, seed rain, post-fire management, colonization, microhabitat.

\section{Introduction}

Mediterranean plant communities have been defined as resilient to fire (Lavorel 1999) because of the widespread occurrence of persistence organs and the strong recovery 
capacity found in vegetation. After a disturbance, plants regenerate by two main strategies, resprouting and seed germination, depending on each species' life traits (Pausas 2001, Buhk et al. 2007). Resprouters are plants that shoot buds from undamaged lignotuber, epicormic tissues, rhizomes, roots, etc. Seeders have dry fruits with small seeds which germinate from the seed bank after heat stimulus caused by fire (Verdú 2000, Keeley \& Fotheringham 2000). Both regeneration strategies allow most Mediterranean plant communities to regenerate directly in a process that has been called autosuccession, that is, the fast recovery of a plant community with the same species pool that it had before the disturbance (Trabaud \& Lepart 1980). However, not all plant communities are capable of direct regeneration (Rodrigo et al. 2004) and even if they were, propagule colonization could play an unnoticed role in post-disturbance succession.

Seed dispersal, by different agents, is the natural process that is most important in allowing plant colonization of disturbed habitats (Neeman \& Izhaki 1996). Directed dispersal by animals towards locations with particular characteristics is fundamental for successful seedling establishment and recruitment (Howe \& Smallwood 1982, Schupp $\&$ Fuentes 1995). In the Mediterranean Basin the fruit of most fleshy-fruited plants ripens in autumn-winter, when it can be consumed by carnivore mammals and by wintering and resident frugivorous birds. These endozoochorous vertebrates digest the fruit pulp but defecate the viable seeds at some distance from the mother plant. In general, fleshy-fruited plants have big, short-life seeds that are killed by heat, and resprout after fire (Pausas \& Verdú 2005). During the first months following the fire, these plants dedicate their strength to vegetative growth, and most of them do not bear fruit until more than a year after the fire. Throughout this initial period, the endozoochorous dispersal of their seeds from unburned habitats to burned areas could play a role in regeneration. However, this process remains to be studied (but see Cowling et al. 1997).

The pattern and composition of the seed rain can determine the regenerative potential of fleshy-fruited plants dispersed by endozoochorous vertebrates (Howe \& Smallwood 1982, Schupp \& Fuentes 1995). Factors that influence the composition of the seed rain include the density, distribution and fecundity of the seed sources in the vicinity, the spatial pattern of dispersal by the agents involved, and landscape features, such as perch availability for birds, that influence seed deposition (Murray 1988, Izhaki et al. 1991). Post-fire management, such as salvage logging operations, may take place after a forest fire. Logging alters the habitat use of birds, including frugivorous species (Llimona et al. 1993, Izhaki \& Adar 1997, Herrando et al. in press), and could therefore affect the quantity and spatial distribution of dispersed seeds belonging to fleshy-fruited plants. Hence, the removal of perches (surviving trees, snags and burned branches) could be a critical issue, because of the importance of perches in seed deposition patterns originating from bird transport (Guevara \& Laborde 1993, Pausas et al. 2006, Herrera \& García 2009). 
We took advantage of a large area of Mediterranean forest and shrubland that had recently been severely burned to investigate the magnitude of seed dispersal of fleshyfruited plants by birds (i.e. seed rain). Since the plants of the burned area had not yet come to fruition during the study, all the collected seeds originated in unburned areas, which made it possible to assess genuine seed colonization in a disturbed area. A second aim of this study was to analyse the effects of post-fire management on seed rain by birds. In this connection, we predicted that the removal of perches would negatively affect the magnitude of seed rain in burned and managed forests.

\section{Methods}

\section{Study area and post-fire management}

The study was carried out in the Santa Caterina valley $\left(3^{\circ} 7^{\prime} \mathrm{E}, 42^{\circ} 3^{\prime} \mathrm{N}\right)$, in the Montgrí massif (Catalonia, in the north-east of the Iberian Peninsula). This is a limestone area with a meso-Mediterranean climate. In September 2004 a wildfire burned 627 ha of Aleppo pine forest (Pinus halepensis), shrubland, rocky outcrops and crops. It was a severe fire which affected the forest canopy and undergrowth and caused widespread tree mortality. The study was conducted in the second winter after the fire (winter 200607) in a burned area of c. 90 ha, and in an unburned control area at a distance of $2 \mathrm{~km}$ (Figure 1). The vegetation in the burned area was at an early regeneration stage and consisted of low shrubs (Kermes oak Quercus coccifera, Evergreen pistache Pistacia lentiscus, rock roses Cistus spp.), climbing plants (Rough bindweed Smilax aspera, Wild madder Rubia peregrina and Wild asparagus Asparagus acutifolius) and grass (Brachypodium retusum). Within the burned study area only one patch of 2 ha was unburned. This patch was the nearest source of seeds (of native fleshy-fruit shrubs, some planted olive trees Olea europaea var. europaea and European hackberries Celtis australis). We knew this because we visually inspected the burned area and verified that fleshy-fruited plants were not fruiting in the regenerating shrubland. The unburned control area was an Aleppo pine forest unburned for the latest 50 years and with welldeveloped undergrowth.

Most of the burned study area (c. 70 ha) was managed for timber harvesting. It was public property so homogeneous salvage logging, consisting of felling almost all pine snags but leaving 5-10 standing snags/ha, was carried out. Non-commercially profitable logs and branches were piled along the contour lines in order to avoid soil erosion in this rugged terrain. The size of these barriers ranged between 0.5 and $1 \mathrm{~m}$ high and 3-10 $\mathrm{m}$ long (Figure 2a). The density of barriers was very high in some areas, reaching 100 barriers/ha (Figure 2b). Open areas, covered by regenerated low shrub vegetation, were found between the barriers. The rest of the burned study area (patches totalling up to 1520 ha) was not managed and pine snags (200-400 snags/ha) remained standing until they fell naturally in following years. Finally, the unburned control Aleppo pine forest was unmanaged. 


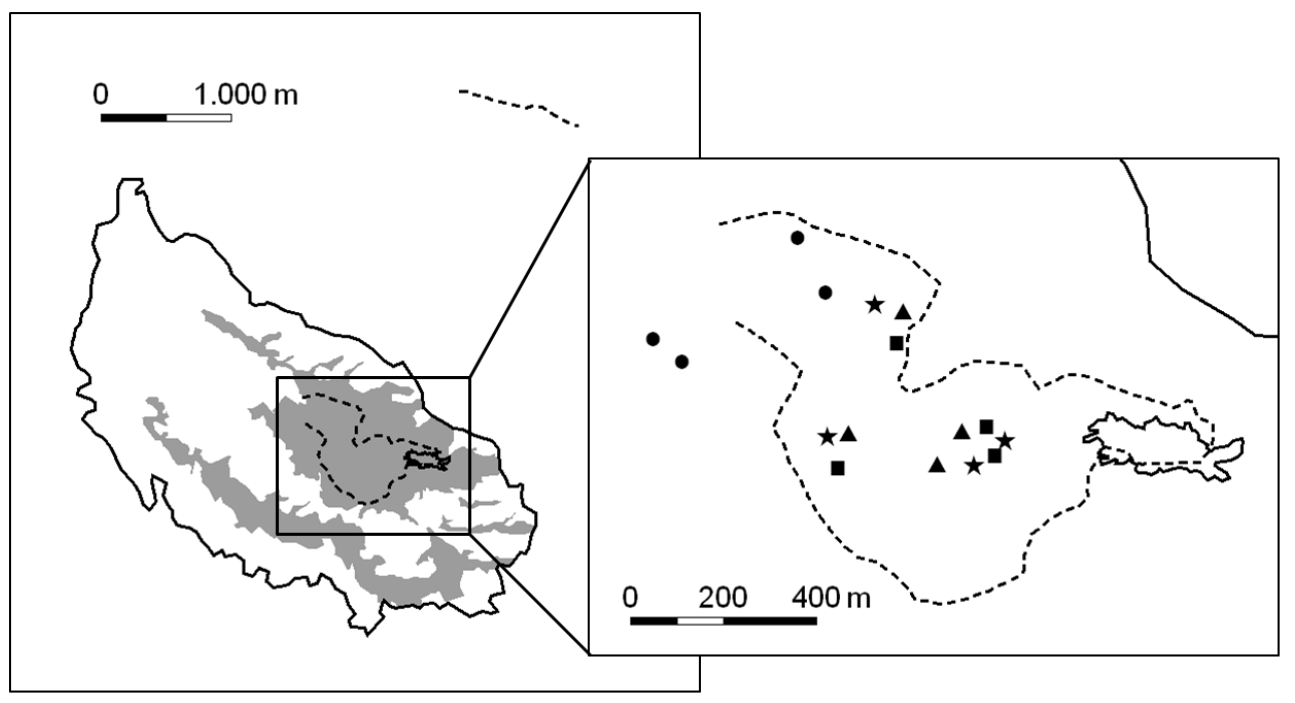

Figure 1. Left: Area burned by the 2004 wildfire (the solid line is the fire perimeter) and location of the bird census transects in burned and unburned areas (dashed lines); the extent of pine forest is shown in grey and the square shows the area enlarged at right. Right: location of the bird transect and seed trap sites in the burned study area (circles: unlogged; stars: barriers; squares: open areas; triangles: isolated trees; the last three microhabitats were located in logged areas) The two-hectare unburned patch is also drawn.

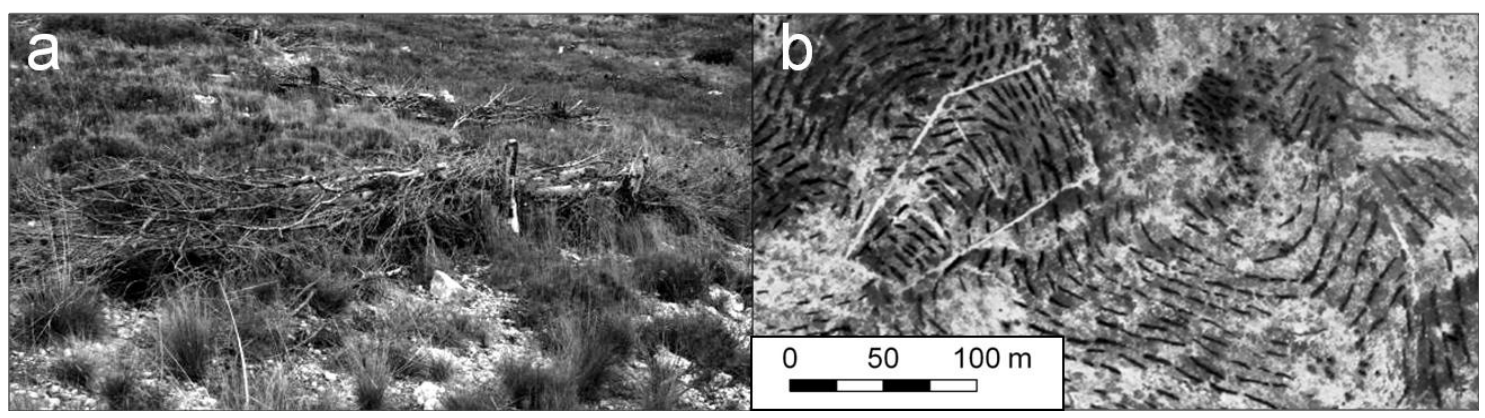

Figure 2. Log and branch erosion barriers in the study area. (a) A typical barrier; (b) Aerial photograph showing the distribution of barriers (dark lines).

\section{Frugivorous bird sampling}

Bird censuses were conducted once a month, from November to February, in order to record frugivorous species that could potentially disperse the seeds of fleshy-fruited plants. A line transect (Bibby et al. 1992) $3.3 \mathrm{~km}$ long was carried out within the burned study area (Figure 1). Approximately $40 \%$ of the total length of the transect passed through unlogged areas, while the rest was in salvage logged areas. A second transect (900 m long) was carried out in the unburned control area. Bird species occurrence was recorded within a band $40 \mathrm{~m}$ wide on each side of the pathway. We defined three microhabitats in the logged area: isolated snags, barriers and open areas. The location of birds among the three microhabitats was recorded in order to assess the microhabitat use of frugivorous species. We also classified bird species as fleshy-fruit plant dispersers in line with the available information for the Mediterranean region in autumn-winter (Herrera 1984, 1998). 


\section{Management effects on seed rain}

Dispersion of fleshy-fruited plant seeds by birds was assessed in the five microhabitats resulting from management or its absence: unburned control forest, burned unlogged forest, and isolated snags, barriers and open areas in the burned logged forest. Seeds were collected using seed traps installed under perches from where birds could defecate. Perches consisted of living trees, snags, isolated snags, barriers or resprouting sprouts, depending on the microhabitat. Seed traps consisted of circular $0.07 \mathrm{~m}^{2}$ plastic trays with a height of $4 \mathrm{~cm}$. Each tray was covered by a $0.7 \mathrm{~cm}^{2}$ wire mesh to prevent seed predation by rodents and birds. A sampling unit was made up of five of these traps put together and separated by $0.5 \mathrm{~m}$ from each other below the same perch. Four sampling units were set up in each microhabitat. Sampling units of the different microhabitats were interspersed in the available area. However, as management was not under our control, unlogged sites could not be interspersed with the other three microhabitats in the burned area (Figure 1). Sampling units, within and among microhabitats, were located at different distances from the nearest seed-source areas (unburned pinewood patch and burned area perimeter), ranging between 200 and 2,500 $\mathrm{m}$ from these sources. The seed traps were installed in November and checked monthly until early March. Once the seeds had been collected, they were counted and identified using a reference seed collection. We then obtained the dispersed seed density per plant species in each sampling unit, by dividing the number of seeds collected by the sampling unit area.

\section{Data analysis}

We used general linear mixed models (GLMM) to assess whether the distance from the seed source area affects the density of seeds found in traps. To this aim we used only the microhabitats where seed rain had to come from a distant seed source, thereby, excluding the unburned control. Seed density was the dependent variable in the GLMM, the distances between each replicate and the seed sources were the explicative variables and the four microhabitats from the burned area were the random factor, in order to control their possible effect on seed rain. We tested the seed results for the native shrubland species (Evergreen pistache, Wild asparagus, Rough bindweed and Wild madder) together since we assumed they had a common potential origin (i.e. the unburned patch and the unburned shrubland adjacent to the burned area perimeter). We separately tested the seed results of the Olive trees with a potential origin in the unburned patch and in the groves to the south and on the west side of the burned area. In both cases we used, alternately, the minimum distance to the nearest potential source (usually the unburned patch) and the mean distance between the two/three nearest potential sources as the explicative variable in the model.

We also performed ANOVA tests to detect differences in seed dispersal between microhabitats and plant species. For a first analysis, we used the seeds collected for all the plant species together, and we conducted two more, separate, tests for the Olive tree 
and the Evergreen pistache, the two most dispersed species. In all cases, seed density was the dependent variable and microhabitats were the categorical predictors. Post-hoc differences were tested with Tukey tests. Seed density was square root transformed in order to fit the normality assumption. Statistical tests were performed with STATISTICA 8 software (StatSoft Inc. 2001). In all cases we considered $P<0.05$ as being statistically significant.

\section{Results}

\section{Frugivorous birds}

We found 25 bird species in transect censuses, eight of which have a frugivorous diet in autumn-winter. These species were both forest species (found in the control and burned sites) and open-habitat ones: European Robin (Erithacus rubecula), Black redstart (Phoenicurus ochruros), Stonechat (Saxicola torquata), Blackbird (Turdus merula), Song thrush (Turdus philomelos), Sardinian warbler (Sylvia melanocephala), Dartford warbler (Sylvia undata) and Blackcap (Sylvia atricapilla) (Table 1). Frugivorous bird richness reached its highest value in wood debris barriers $(66.7 \%$ of the total number of bird species), followed by open areas (46.2\%), unburned control (35.3\%), snags in the unlogged area $(30.0 \%)$ and isolated snags $(15.4 \%)$. The eight frugivorous species were observed in the barriers, with Sylvia warblers being especially frequent, and six of them were found in the open area around the barriers (although less frequently), or perched on the isolated snags of the logged area (occasionally). On the other hand, Turdus thrushes were the only species recorded in unlogged areas.

Table 1. Frequency of occurrence of frugivorous bird species in the five microhabitats (CO: unburned control, UN: burned unlogged, IS: isolated snags, OP: open area and BA: barriers) obtained from the four monthly censuses.

\begin{tabular}{llllll}
\hline & \multicolumn{2}{l}{ Microhabitat } & & \\
\hline Species & CO & UN & IS & OP & BA \\
\hline European Robin Erithacus rubecula & 0.75 & & & & 0.25 \\
Black redstart Phoenicurus ochruros & & & & 0.50 & 0.50 \\
Stonechat Saxicola torquata & & & & 0.75 & 0.75 \\
Blackcap Sylvia atricapilla & 0.50 & & & & 0.75 \\
Sardinian warbler Sylvia melanocephala & 1.00 & & 0.25 & 0.25 & 1.00 \\
Dartford warbler Sylvia undata & & & 0.25 & 0.50 & 1.00 \\
Blackbird Turdus merula & 1.00 & 0.50 & & 0.25 & 0.50 \\
Song thrush Turdus philomelos & 0.75 & 0.75 & & & 0.25 \\
\hline Total richness & 5 & 2 & 2 & 5 & 8 \\
\hline
\end{tabular}

\section{Seed rain and management effect}

We collected a total of 135 seeds of six fleshy-fruit plant species: Olive tree, $\mathrm{N}=83$; Evergreen pistache, $\mathrm{N}=37$; Wild asparagus, $\mathrm{N}=10$; Rough bindweed, $\mathrm{N}=2$; European hackberry, $\mathrm{N}=1$; and Wild madder, $\mathrm{N}=1$. The highest densities of Olive tree seeds were 
found in barriers, whereas Evergreen pistache was much more dispersed in the unburned control forest (Table 2).

The distance from the potential seed sources to the sampling sites had no significant effect on seed dispersal (Table 3) either for native plant species or for Olive trees. However, microhabitat affects significantly the seed rain of olives. The ANOVA revealed significant differences in seed dispersal between microhabitats $\left(\mathrm{F}_{4,15}=5.18, P\right.$ $<0.01)$. The barrier and unburned control microhabitats had the highest values of seed density, reaching more than ten seeds $/ \mathrm{m}^{2}$ in the four-month sampling period. The lowest values were found in the burned unlogged, open area, and in especially, isolated snag microhabitats (Figure 3). However, post-hoc testing only showed that unburned control and barrier microhabitats were significantly different from the isolated snag microhabitats. Nevertheless, the effect of microhabitat depended on plant species: being significant for both Olive tree $\left(\mathrm{F}_{4,15}=3.21, P=0.04\right)$ and Evergreen pistache $\left(\mathrm{F}_{4,15}=\right.$ 4.60, $P=0.01)$. Post-hoc comparisons show that significant differences existed between barriers and selective logging microhabitats for the Olive tree, and between the unburned control and burned unlogged, selective logging and open areas microhabitats for the Evergreen pistache (Figure 3).

Table 2. Mean density (in seeds $/ \mathrm{m}^{2} \pm$ standard error) of fleshy fruit plant seeds collected in traps per microhabitat (CO: unburned control, UN: burned unlogged, IS: isolated snags, OP: open area and BA: barriers).

\begin{tabular}{llllll}
\hline & CO & UN & IS & OP & BA \\
\hline Olive tree Olea europaea & $13.44 \pm 7.0$ & $7.78 \pm 4.9$ & $0.71 \pm 0.7$ & $8.49 \pm 3.1$ & $19.10 \pm 7.9$ \\
Evergreen pistache Pistacia lentiscus & $16.98 \pm 4.8$ & $2.12 \pm 1.3$ & $2.12 \pm 0.7$ & $3.54 \pm 2.7$ & $3.54 \pm 0.7$ \\
Wild asparagus Asparagus acutifolius & $4.24 \pm 1.8$ & $2.12 \pm 1.3$ & - & - & $2.83 \pm 2.0$ \\
Rough bindweed Smilax aspera & $0.71 \pm 0.7$ & - & - & - & $0.71 \pm 0.7$ \\
European hackberry Celtis australis & - & - & - & - & $0.71 \pm 0.7$ \\
Wild madder Rubia peregrina & - & - & - & - & $0.71 \pm 0.7$ \\
\hline
\end{tabular}
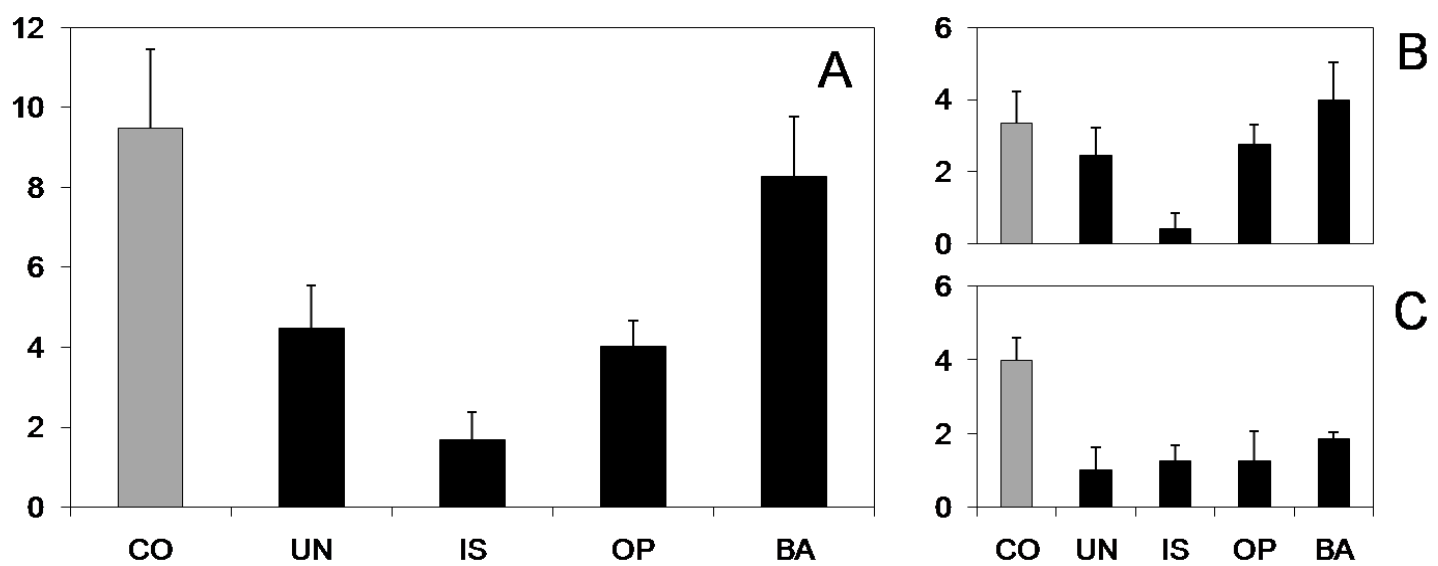

Figure 3. Mean density of collected seeds per square meter (square root transformed) in each microhabitat. A: sum of all plant species; B: Olive tree seeds; C: Evergreen pistache seeds. Black bars correspond to burned sites (CO: unburned control, UN: burned unlogged, IS: isolated snags, OP: open area and BA: barriers). Error bars indicate standard error. 
Table 3. Linear regression analysis between seed density and distance from the nearest seed source, using microhabitats as the random factor.

\begin{tabular}{cllll}
\hline & SS & df & F & $p$ \\
\hline Native shrub species & & & & \\
Nearest source & & & & \\
Distance & 8.79 & 1 & 0.66 & 0.432 \\
$\quad$ Microhabitat & 76.45 & 3 & 1.93 & 0.183 \\
Average 2 nearest sources & & & & \\
$\quad$ Distance & 1.10 & 1 & 0.08 & 0.784 \\
$\quad$ Microhabitat & 70.61 & 3 & 1.69 & 0.226 \\
Olea europaea & & & & \\
Nearest source & & & & \\
$\quad$ Distance & 0.31 & 1 & 2.67 & 0.130 \\
$\quad$ Microhabitat & 2.40 & 3 & 6.86 & 0.007 \\
Average 3 nearest sources & & & & \\
$\quad$ Distance & 0.26 & 1 & 2.17 & 0.169 \\
Microhabitat & 2.25 & 3 & 6.19 & 0.010 \\
\hline
\end{tabular}

\section{Discussion}

Our results show that there exists a bird-dependent seed rain in Mediterranean burned and managed forests, originating from seed sources in unburned areas. Furthermore, the quantity of seeds coming into a burned area is not very different in magnitude from the seed rain measured in nearby unburned forests. However, the density of seeds found in burned logged forests was heterogeneous, which suggests that habitat and microhabitat do have an important effect on seed rain (Debussche \& Isenmann 1994, Kollmann \& Pirl 1995, Milton et al. 1997).

Seed dispersal of fleshy-fruited plants can be affected by the different occupancy of microhabitats by frugivorous birds. The highest seed density in the burned area was concentrated in wood barriers, which may be attributable to the frequency of frugivorous bird species in this microhabitat. Bird species recorded in barriers usually occur in low vegetation, such as open shrublands or forest undergrowth, and wood barriers may favour their presence since these structures are the main perches in the short term after fire, when shrub regeneration is still very limited. Birds may actively use wood barriers for shelter, roosting, perching and even as feeding points. Even without fruiting plants, coarse woody debris can be a source of macro-arthropods in winter (Jabin et al. 2004, Varady-Szabo \& Buddle 2006), and the majority of the frugivorous species we found also have an insectivore component in their diet (Snow \& Perrins 1998). Consequently, the higher use of the barriers by frugivorous-insectivorous birds could be the cause of the higher seed dispersion rate in this microhabitat. Besides, such widely different microhabitats as unlogged burned patches and open areas both show evidence of a similar seed rain. The intermediate seed density found in completely logged areas could be due to the close proximity of barriers, from where frugivorous birds can occasionally visit the surrounding area. This edge effect at small scale may increase the seed rain in those open areas. In contrast, the similar seed density found in unlogged burned patches can be explained by the fact that only thrushes were found in such areas. On the other hand, few bird species used the isolated snags resulting from 
selective logging, probably because of the lack of a suitable canopy cover, a snag density that is too low for thrushes, and because warblers do not usually perch on the highest branches. Therefore, contrary to our predictions, remaining isolated snags do not seem to act as dispersal sites for frugivorous bird depositions in such areas. Nevertheless, we showed that the effect of microhabitat on seed rain varies with the seed species. Such differences may stem from the local availability of each plant fruits, since Evergreen pistache fruits are probably much more abundant in unburned control, where seed rain has found to be higher, than Olive tree fruits, where it is not a common plant.

The Olive tree, a cultivated variety grown in nearby groves, was the species for which more seeds were found. Despite its high seed dispersal rate in the study area, its postdispersal seeding capability seems very limited in natural conditions, and it is not considered an invasive species. Large thrushes (Song Thrush and Blackbird) are probably responsible for the dispersal of these seeds, since the gape size of birds limits the swallowing of large olive fruits (Rey et al. 1997). Hence, smaller frugivores should be considered as pulp peckers (Herrera 1984, Rey \& Gutiérrez 1996) and not seed dispersers of commercial olive trees. On the other hand, the smaller fruits of native species may have been dispersed either by thrushes or by other major frugivores (mainly Sylvia warblers and the European Robin, see Herrera 1995). However, despite thrushes being scarcer than other species in barriers, that is where commercial olive seed rain reached its highest value (Table 2). Furthermore, the fact that we could not find an effect of distance from seed sources on seed density suggests that bird dispersers can move considerable distances between the burned and the unburned area. Jordano et al. (2006) found that small-sized frugivores (warblers) rarely disperse seeds at more than $100 \mathrm{~m}$, and the nearest seed source was at c. $200 \mathrm{~m}$ to its nearest sampling unit. This also suggests that the majority of seed dispersal in our area is attributable to thrushes, the largest bird dispersers found in the burned area.

Bird depositions produce a directed, non-random seed rain (Murray 1988, Izhaki et al. 1991, Herrera et al. 1994). Nevertheless, the number of dispersed seeds is only a quantitative factor (Schupp 1993) since plant recruitment depends also on the microhabitat's suitability for seedling emergence and establishment (the nurse-plant effect), including factors such as competition, light intensity, temperature, soil conditions, rodent predation and herbivore damage (Tewksbury \& Lloyd 2001, Kollmann 2000, García \& Obeso 2003). Although wood barriers only represent a 5$10 \%$ of a burned and managed forest area, and therefore the absolute seed rain is probably not higher there than over other more extensive microhabitats, barriers may be more suitable because of their similarity to shrubs, where the germination of certain species is higher (García-Fayos \& Verdú 1998). However, seed predation by rodents tends to be more intense under shrubs than in open areas (Kollmann 1995, Hulme 1996), and wood piles can benefit certain rodents (Manning \& Edge 2008). Therefore, further investigation is needed to evaluate whether bird-dispersed seeds can successfully establish themselves in those microhabitats so that they can act as recruitment sites for 
fleshy-fruited plants. If they could, the differential seed rain between microhabitats would lead to a heterogeneous distribution of fleshy-fruited plants in burned and managed areas in which a fine-grained mosaic of structures (isolated snags, wood barriers and open areas derived from logging) occurs. In contrast to our study area, small, privately-owned forest properties are the rule in Catalonia, a pattern that promotes patchy management. And finally, there needs to be further investigation into frugivorous bird distribution in autumn-winter in burned areas, in order to determine their habitat and microhabitat relationships more accurately, and to assess the effects of post-fire management on these species.

\section{Acknowledgements}

The authors thank two anonymous referees for their valuable comments on an earlier draft of this paper. This study was funded by the Spanish Ministry of Science and Innovation (CGL2005-0031/BOS and CGL2008-05506/BOS) and J.R. held a FPU grant of the same ministry.

\section{References}

Bibby, C.J., Burgess, N.D. \& Hill, D.A. 1992. Bird census techniques. Cambridge University Press, Cambridge.

Buhk, C., Meyne, A. \& Jentsch, A. 2007. The challenge of plant regeneration after fire in the Mediterranean Basin: scientific gaps in our knowledge on plant strategies and evolution of traits. Plant Ecology 192, 1-19.

Cowling, R.M., Kirkwood, D., Midgley, J.J. \& Pierce, S.M. 1997. Invasion and persistence of birddispersed, subtropical thicket and forest species in fire-prone coastal fynbos. Journal of Vegetation Science 8, 475-488.

Snow, D. \& Perrins, C. (eds.). 1998. The complete Birds of the Western Palearctic on CD-ROM. Oxford University Press, Oxford.

Debussche, M. \& Isenmann, P. 1994. Bird-dispersed seed rain and seedling establishment in patchy Mediterranean vegetation. Oikos 69, 414-426.

deWolfe, V.G., Santi, P.M., Ey, J. \& Gartner J.E. 2008. Effective mitigation of debris flows at Lemon Dam, La Plata County, Colorado. Geomorphology 96, 366-377.

García, D. \& Obeso, J.R. 2003. Facilitation by herbivore-mediated nurse plants in a threatened tree, Taxus baccata: local effects and landscape level consistency. Ecography 26, 739-750.

García-Fayos, P. \& Verdú, M. 1998. Soil seed bank, factors controlling germination and establishment of a Mediterranean shrub: Pistacia lentiscus L. Acta Oecologica 19, 357-366.

Guevara, S. \& Laborde, J. 1993. Monitoring seed dispersal at isolated standing trees in tropical pastures consequences for local species availability. Vegetatio 108, 319-338.

Herrando, S., Brotons, L., Guallar, S., Sales, S. \& Pons, P. 2009. Postfire forest management and Mediterranean birds: the importance of logging remnants. Biodiversity and Conservation 18, 2153-2164. 
Herrera, C.M. 1984. A study of avian frugivores, bird-dispersed plants, and their interaction in Mediterranean scrublands. Ecological Monographs 54, 1-23.

Herrera, C.M. 1995. Plant-vertebrate seed dispersal systems in the Mediterranean: ecological, evolutionary, and historical determinants. Annual Review of Ecology Evolution and Systematics $26,705-727$

Herrera, C.M. 1998. Long-term dynamics of Mediterranean frugivorous birds and fleshy fruits: a 12-year study. Ecological Monographs 68, 511-538.

Herrera, C.M., Jordano, P., López-Soria, L. \& Amat, J.A. 1994. Recruitment of a mast-fruiting, birddispersed tree: bridging frugivore activity and seedling establishment. Ecological Monographs 64, 315-344.

Herrera, J.M. \& García, D. 2009. The role of remnant trees in seed dispersal through the matrix: Being alone is not always so sad. Biological Conservation 142, 149-158.

Howe, H.F. \& Smallwood, J. 1982. Ecology of seed dispersal. Annual Review of Ecology Evolution and Systematics 13, 201-228.

Hulme, P.E. 1996. Natural regeneration of yew (Taxus baccata L.): microsite, seed or herbivore limitation? Journal of Ecology 84, 853-861.

Izhaki, I., Walton, P.B. \& Safriel, U.N. 1991. Seed shadows generated by frugivorous birds in an eastern Mediterranean scrub. Journal of Ecology 79, 575-590

Izhaki, I. \& Adar, M. 1997. The effects of post-fire management on bird community succession. International Journal of Wildland Fire, 7, 335-342.

Jabin, M., Mohr, D., Kappes, H. \& Topp, W. 2004. Influence of deadwood on density of soil macroarthropods in a managed oak-beech forest. Forest Ecology and Management 194, 61-69.

Jordano, P., García, C., Godoy, J.A. \& García-Castaño, J.L. 2006. Differential contribution of frugivores to complex seed dispersal patterns. Proceedings of the National Academy of Sciences of the United States of America 104, 3278-3282.

Keeley, J. E. \& Fotheringham, C.J. 2000. Role of fire in regeneration from seed. In: Fenner, M. (ed.). Seeds: the ecology of regeneration in plant communities. C.A.B. International, Wallingford. Pp 311-330.

Kollmann, J. \& Pirl, M. 1995. Spatial pattern of seed rain of fleshy-fruited plants in a scrubland-grassland transition. Acta Oecologica 16, 313-329.

Kollmann, J. 1995. Regeneration window for fleshy-fruited plants during scrub development on abandoned grassland. Écoscience 2, 213-222.

Kollmann, J. 2000. Dispersal of fleshy-fruit species: a matter of spatial scale? Perspectives in Plant Ecology, Evolution and Systematics 3, 29-51.

Lavorel, S. 1999. Ecological diversity and resilience of Mediterranean vegetation to disturbance. Diversity and Distributions 5, 3-13.

Llimona, F., Matheu, E. \& Prodon, R. 1993. Role of snag persistence and of tree regeneration in postfire bird successions: comparison of pine and oak forests in Montserrat (Catalonia, NE Spain). In: Trabaud, L. \& Prodon, R. (eds.). Fire in Mediterranean Ecosystems. Ecosystems Research Report, 5. Commission of the European Communities, Bruxelles. Pp. 315-331.

Malanson, G. P. 1987. Diversity, stability and resilience: effect of fire regimes. In: Trabaud L. (ed.). The role of fire in ecological systems. SPB Academic Publishing, The Hague. Pp. 49-63

Manning, J.A. \& Edge, W.D. 2008. Small mammal responses to fine woody debris and forest fuel reduction in southwest Oregon. Journal of Wildlife Management 72, 625-632. 
Milton, S.J., Dean, W.R.J. \& Klotz, S. 1997. Thicket formation in abandoned fruit orchards: processes and implications for the conservation of semi-dry grasslands in Central Germany. Biodiversity and Conservation 6, 275-290.

Murray, K.G. 1988. Avian seed dispersal of three neotropical gap-dependent plants. Ecological Monographs 58, 271-298.

Neeman G. \& Izhaki, I. 1996. Colonization in an abandoned East-Mediterranean vineyard. Journal of Vegetation Science 7, 465-472.

Pausas, J.G. 2001. Resprouting vs. seeding -a Mediterranean perspective. Oikos 94, 193-194.

Pausas, J.G. \& Verdú, M. 2005. Plant persistence traits in fire-prone ecosystems of the Mediterranean basin: a phylogenetic approach. Oikos 109, 196-202.

Pausas, J.G., Bonet, A., Maestre, F. T. \& Climent, A. 2006. The role of the perch effect on the nucleation process in Mediterranean semi-arid oldfields. Acta Oecologica 29, 346-352.

Raftoyannis, Y. \& Spanos, I. 2005. Evaluation of $\log$ and branch barriers as post-fire rehabilitation treatments in a Mediterranean pine forest in Greece. International Journal of Wildland Fire 14, $183-188$.

Rey, P.J. \& Gutiérrez, J.E. 1996. Pecking of olives by frugivorous birds. A shift in feeding behaviour to overcome gape limitation. Journal of Avian Biology 27, 327-333,

Rey, P.J., Gutiérrez, J.E., Alcántara, J. \& Valera, F. 1997. Fruit size in wild olives: implication for avian seed dispersal. Functional Ecology 11, 611-618.

Rodrigo, A., Retana, J. \& Pico, X. 2004. Direct regeneration is not the only response of Mediterranean forests to large fires. Ecology 85, 716-729.

Schupp, E.W. 1993. Quantity, quality and the effectiveness of seed dispersal by animals. Vegetatio $107 / 108,15-29$

Schupp, E.W. \& Fuentes, M. 1995. Spatial patterns of seed dispersal and the unification of plant population ecology. Écoscience 2, 267-275.

StatSoft, Inc. 2001. STATISTICA for Windows [Computer program manual]. StatSoft Inc., Tulsa.

Tewksbury, J.J. \& Lloyd, J.D. 2001. Positive interactions under nurse-plants: spatial scale, stress gradients and benefactor size. Oecologia 127, 425-434

Trabaud, L. \& Lepart, J. 1980. Diversity and stability in garrigue ecosystems after fire. Vegetatio 43, 4957.

Varady-Szabo, H. \& Buddle, C.M. 2006. On the relationships between ground-dwelling spider (Araneae) assemblages and dead wood in a northern sugar maple forest. Biodiversity and Conservation 15, 4119-4141.

Verdú, M. 2000. Ecological and evolutionary differences between Mediterranean seeders and resprouters. Journal of Vegetation Science 11, 265-268. 